\title{
INFLUÊNCIA DA APLICAÇÃO DE ÁGUAS RESIDUÁRIAS DE SUINOCULTURA NA CAPACIDADE DE INFILTRAÇÃO DE UM SOLO PODZÓLICO VERMELHO-AMARELO ${ }^{1}$
}

\author{
Rubens Alves Oliveira², Paulo Luis Gonçalves Campelo ${ }^{3}$, Antônio Teixeira Matos ${ }^{4}$, \\ Mauro Aparecido Martinez ${ }^{4}$ \& Paulo Roberto Cecon ${ }^{4}$
}

\begin{abstract}
RESUMO
Este trabalho foi conduzido na Área Experimental de Hidráulica, Irrigação e Drenagem do Departamento de Engenharia Agrícola da Universidade Federal de Viçosa, em Viçosa, MG, com o objetivo de se avaliar a influência de aplicações sucessivas de águas residuárias de suinocultura, com diferentes concentrações de sólidos totais sobre a capacidade de infiltração de um solo Podzólico Vermelho-Amarelo. O experimento foi conduzido em delineamento experimental inteiramente casualizado, com cinco tratamentos e três repetições, em que os tratamentos se constituíram da aplicação de água e de águas residuárias com concentrações de sólidos totais de 2,4, 7,0,16,3 e 26,9 $\mathrm{g} \mathrm{L}^{-1}$. Quinze infiltrômetros de anel foram instalados em uma área de $60 \mathrm{~m}^{2}$, dividida em parcelas de dimensões $2 \times 2 \mathrm{~m}$, sendo que em cada uma delas foram conduzidos quatro testes de infiltração, com intervalo de 15 dias. Concluiu-se que o aumento da concentração de sólidos totais de águas residuárias de suinocultura provocou redução na capacidade de infiltração do solo, intensificada com aplicações sucessivas. A concentração de sólidos totais desse efluente foi mais importante na redução da capacidade de infiltração do solo que os níveis de razão de adsorção de sódio e de salinidade.
\end{abstract}

Palavras-chave: infiltração, água residuária, podzólico vermelho-amarelo

\section{INFLUENCE OF SWINE WASTEWATER APPLICATION ON THE INFILTRATION CAPACITY OF A YELLOW-RED PODZOL}

\begin{abstract}
This work was carried out at the Experimental Area of Hydraulics, Irrigation and Drainage of the Agricultural Engineering Department, at the Federal University of Viçosa, Viçosa, Minas Gerais, Brazil. The aim was to evaluate the influence of successive applications of swine wastewater, with different concentrations of total solids, on the infiltration capacity of a Yellow Red Podzol. The experiment was conducted in a completely randomized design with five treatments and three replications. The treatments consisted of applying water and swine wastewater with 2.4, 7.0, 16.3 and $26.9 \mathrm{~g} \mathrm{~L}^{-1}$ of total solid concentrations. Fifteen ring infiltrometers were installed in an area of $60 \mathrm{~m}^{2}$, which was divided in plots of $2 \times 2 \mathrm{~m}$ dimensions. Four infiltration tests were performed at 15 day intervals in each plot. It was concluded that increasing the total solid concentration of swine wastewater caused a reduction of the soil infiltration capacity. In addition, it was observed that successive applications intensified this effect. The total solid concentration of wastewater was more important to reduce the soil infiltration capacity than the levels of sodium absorption ratio and salinity.
\end{abstract}

Key words: infiltration, wastewater, yellow red podzol

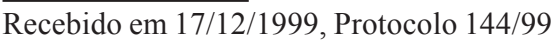

${ }^{1}$ Projeto financiado pela FAPEMIG

${ }^{2}$ Professor Adjunto Doutor, Departamento de Engenharia Agrícola, Universidade Federal de Viçosa, Viçosa, MG. Fone: (0xx31) 899 1909, Fax: (0xx31) 899 2735.E-mail: ralves@mail.ufv.br

${ }^{3}$ Engenheiro Agrícola, Mestre, Departamento de Engenharia Agrícola, Universidade Federal de Viçosa, Viçosa, MG

${ }^{4}$ Professor Doutor, Universidade Federal de Viçosa, Viçosa, MG. E-mail: atmatos@mail.ufv.br, mmauro@mail.ufv.br, cecon@dpi.ufv.br 


\section{INTRODUÇ̃̃O}

A suinocultura é uma exploração pecuária concentradora de dejetos animais, possuidores de alta carga poluidora para o solo, o ar e a água; por isso, nos últimos 15 anos muitos estudos têm sido conduzidos, buscando-se o desenvolvimento de tecnologias que viabilizem a utilização desses dejetos, minimizando seu impacto sobre o ambiente (Matos et al., 1997).

De acordo com Ayers \& Westcot (1987) a agricultura utiliza maior quantidade de água e pode tolerar águas de qualidade mais baixa que a indústria e o uso doméstico; é inevitável, portanto, que exista crescente tendência para se encontrar na agricultura a solução dos problemas relacionados com efluentes. Em termos quantitativos, o volume de águas residuárias disponíveis para a irrigação é insignificante em comparação com o total de água usado em agricultura irrigada, mas as possíveis conseqüências de seu uso são de tal importância econômica, ambiental e social, que a necessidade de planejamento é justificada para controlar, a longo prazo, os efeitos de salinidade, sodicidade, nutrientes e oligoelementos, sobre os solos e as culturas.

No entanto, os dejetos de animais podem, quando bem manejados, constituir-se em alternativa econômica para a propriedade rural, sem comprometimento da qualidade ambiental. Atualmente, tem-se buscado alternativas para o aproveitamento de dejeto suíno na forma de adubo orgânico e de vermicomposto ou, simplesmente, aplicando-o em solos improdutivos.

Em uma granja de suínos, a quantidade diária de efluentes produzida depende, dentre outros fatores, do número e da idade dos animais e, principalmente, da quantidade de água gasta na higienização das baias. A associação desses fatores, por sua vez, vai definir a concentração de sólidos na água residuária, os custos com estruturas de tratamento ou de armazenamento e a necessidade de área para recebimento dessas águas, como forma de adubação orgânica, caso seja esta a maneira escolhida para disposição do resíduo.

Atualmente, estão sendo recomendadas bombas de alta pressão e baixa vazão para lavagem das baias, buscando-se economizar água nas granjas e diminuir o volume da água residuária produzida, o que é desejável; entretanto, a adoção dessa técnica na higienização das baias implicará em aumento significativo da concentração de sólidos totais da água residuária e, conseqüentemente, da demanda bioquímica de oxigênio.

Irrigação com líquidos com alta concentração de sólidos pode provocar alteração na capacidade de infiltração do solo, ocasionada por entupimento de poros e pela formação de crosta em sua superfície. A formação de crostas superficiais origina problemas de infiltração, de germinação e de emergência de plântulas. Segundo Detar (1980) líquidos contendo mais que $200 \mathrm{mg} \mathrm{L}^{-1}$ de sólidos totais não se infiltrarão no solo em taxas idênticas às observadas com água. Esterco diluído em água pode apresentar velocidade de infiltração equivalente a $1 / 10$ do valor encontrado para água pura.

Considerando-se a escassez de informações técnicas específicas relativas ao tratamento e aproveitamento agrícola de águas residuárias provenientes de atividades suinícolas, cabe à pesquisa o papel de geradora de conhecimentos que possam contribuir na solução de problemas ambientais, propondo alternativas que sejam técnica e economicamente viáveis para a propriedade rural e ambientalmente aceitas pela sociedade.

Com este trabalho objetivou-se estudar o efeito de aplicações sucessivas de água residuária proveniente de higienização de granjas de suínos, com quatro diferentes concentrações de sólidos totais, sobre a capacidade de infiltração do solo.

\section{MATERIAL E MÉTODOS}

Os ensaios foram realizados na Área Experimental de Hidráulica, Irrigação e Drenagem do Departamento de Engenharia Agrícola da Universidade Federal de Viçosa e o experimento foi conduzido em um solo Podzólico VermelhoAmarelo, numa área de $60 \mathrm{~m}^{2}$, dividida em parcelas de dimensões $2 \times 2 \mathrm{~m}$, sendo instalado um infiltrômetro de anel no centro de cada uma delas. Foram estabelecidos cinco tratamentos, um com aplicação de água e os demais com aplicação de água residuária com concentrações de sólidos totais de 2,4, 7,0, 16,3 e 26,9 $\mathrm{g} \mathrm{L}^{-1}$. No experimento foi utilizado o delineamento experimental inteiramente casualizado, com três repetições.

As concentrações de sólidos totais foram: a da água residuária original $\left(2,4 \mathrm{~g} \mathrm{~L}^{-1}\right)$, oriunda de local de descarga de uma granja suinícola, e as três restantes obtidas por adição de uma mistura de fezes e urina coletada no interior das baias de terminação; neste caso, as concentrações de sólidos totais da água residuária foram estimadas aplicando-se a metodologia descrita por Scherer et al. (1995) em que a percentagem de matéria seca é relacionada à massa específica da água residuária proveniente de atividades suinícolas, por meio da seguinte equação:

$$
\mathrm{Y}=-228,72+0,22807 \mathrm{X} \quad \mathrm{R}^{2}=0,96
$$

em que:

Y - matéria seca (\%)

$\mathrm{X}$ - massa específica da água residuária $\left(\mathrm{kg} \mathrm{m}^{-3}\right)$.

Dois reservatórios de cimento amianto foram utilizados no experimento, sendo um para armazenamento de água limpa e o outro para o preparo das misturas relativas a cada concentração de sólidos totais das águas residuárias.

Para condução dos ensaios foram confeccionados 15 infiltrômetros de anel, em PVC, com $25 \mathrm{~cm}$ de diâmetro e $50 \mathrm{~cm}$ de altura, com extremidade inferior biselada, para facilitar a sua cravadura no solo; os infiltrômetros foram cravados até a profundidade de $40 \mathrm{~cm}$ e a bordadura foi constituída de dique feito com terra, construído em volta de cada anel, com altura de aproximadamente $10 \mathrm{~cm}$ e com $50 \mathrm{~cm}$ de diâmetro, sendo que os testes de infiltração foram conduzidos de acordo com metodologia descrita por Bernardo (1995). O modelo potencial foi usado para descrever a infiltração da água e das águas residuárias no solo.

Em cada infiltrômetro foram conduzidos quatro testes, com intervalo de 15 dias, com a finalidade de se avaliar o efeito de irrigações sucessivas na velocidade de infiltração no solo. Com o propósito de possibilitar a obtenção de valores médios de infiltração, os testes foram conduzidos com 42 intervalos de tempo, assim distribuídos: variação de $2 \mathrm{~min}$, até o tempo de 30 min; variação de $5 \mathrm{~min}$, até o tempo de $60 \mathrm{~min}$; variação de 10 
min, até o tempo de 150 min e variação de 30 min, até o tempo de $510 \mathrm{~min}$.

Durante os ensaios agitou-se a massa fluida para evitar sedimentação dos sólidos em suspensão no fundo dos reservatórios, imediatamente antes da aplicação de água residuária nos infiltrômetros e da retirada de amostras para sua caracterização física e química.

A caracterização física da água residuária se deu através da determinação da percentagem de sólidos totais, da massa específica e da condutividade elétrica, enquanto a análise para a determinação da concentração de sólidos totais foi conduzida segundo a metodologia padrão recomendada pela APHA (1995). A massa específica foi obtida determinando-se a massa (balança eletrônica de precisão de $0,1 \mathrm{~g}$ ) de um volume de $200 \mathrm{~mL}$ de água residuária nas diferentes concentrações de sólidos totais estudadas e a condutividade elétrica foi determinada com uso de um condutivímetro eletrônico B331, da marca Micronal.
A caracterização química da água residuária, para as diversas concentrações de sólidos totais estudadas, foi feita por meio da determinação do $\mathrm{pH}$ e dos teores de sódio, fósforo, potássio, cálcio, magnésio, zinco e cobre, além da demanda bioquímica de oxigênio (DBO) segundo a metodologia recomendada pela APHA (1995).

\section{RESULTADOS E DISCUSSÃO}

$\mathrm{Na}$ Tabela 1 estão os resultados das análises da água e das águas residuárias, nas diversas concentrações de sólidos totais utilizadas nos testes de infiltração; concentrações de fósforo e de cobre não foram detectadas na água.

A análise dos dados da Tabela 1 mostra que há tendência de aumento dos níveis dos elementos químicos estudados, à medida que aumentou a concentração de sólidos totais da água residuária. As variações observadas nos dados relativos a uma mesma característica da água residuária foram ocasionadas por

Tabela 1. Caracterização química da água e das águas residuárias de suinocultura




épocas diferentes de coleta, referentes a cada aplicação causadas, principalmente, por mudanças na alimentação e no tratamento sanitário dos animais; já na Tabela 2 estão apresentados valores de razão de adsorção de sódio (RAS) e de condutividade elétrica da água (CEa) calculados com base em valores médios dos dados da Tabela 1. No cálculo da RAS, os valores médios dos níveis de sódio, cálcio e magnésio apresentados na Tabela 1 foram convertidos em unidades de meq $\mathrm{L}^{-1}$. A avaliação da qualidade da água e das águas residuárias, quanto ao potencial de salinização do solo e aos problemas relacionados com infiltração, é baseada nas diretrizes propostas por Ayers \& Westcot (1987). As diretrizes são caráter prático e têm sido usadas na agricultura irrigada para avaliar os constituintes de águas superficiais, subterrâneas e de drenagem, efluentes de esgotos e outras águas residuárias. Não se inclui a avaliação de elementos orgânicos, contidos nas águas residuárias.

Tabela 2. Resultados da avaliação da qualidade da água e das águas residuárias nas diversas concentrações de sólidos totais, utilizadas nos testes de infiltração, quanto aos problemas de infiltração e ao potencial de salinização do solo segundo Ayers $\&$ Westcot (1987)

\begin{tabular}{ccccc}
\hline Fluido & RAS* $^{*}$ & $\mathrm{CE}$ & \multicolumn{2}{c}{ Grau de Restrição para Uso } \\
\cline { 4 - 5 }$\left(\mathrm{mmol} \mathrm{L}^{-1}\right)^{0,5}$ & $\left(\mathrm{dS} \mathrm{m}^{-1}\right)$ & Infiltração & Salinidade \\
\hline Água & 6,2 & 0,1 & Severo & Nenhum \\
$2,4 \mathrm{~g} \mathrm{~L}^{-1}$ & 3,2 & 5,6 & Nenhum & Severo \\
$7,0 \mathrm{~g} \mathrm{~L}^{-1}$ & 2,7 & 7,3 & Nenhum & Severo \\
$16,3 \mathrm{~g} \mathrm{~L}^{-1}$ & 2,9 & 8,4 & Nenhum & Severo \\
$26,9 \mathrm{~g} \mathrm{~L}^{-1}$ & 4,4 & 9,9 & Nenhum & Severo \\
\hline * Razão de adsorção de sódio & & &
\end{tabular}

Os graus de restrição de uso apresentados na Tabela 2 referem-se ao efeito conjunto da razão de adsorção de sódio e da condutividade elétrica da água sobre a capacidade de infiltração do solo. Severa redução da infiltração, por efeitos da qualidade da água, pode ser provocada por uma salinidade muito baixa da água ou por alto valor da razão de adsorção de sódio; neste caso, não é considerado o nível de sólidos totais presentes na água; assim, com base apenas nos dois primeiros parâmetros (RAS e CE) relacionados à qualidade da água para irrigação, ao contrário da água limpa, verifica-se que a água residuária de suinocultura não apresenta potencial de ocasionar problemas de infiltração; por outro lado, é grande o seu potencial de ocasionar salinização do solo.

A Figura 1 mostra as curvas de velocidade de infiltração em função do tempo para água e águas residuárias de suinocultura, nas diversas concentrações de sólidos totais estudadas, para as quatro aplicações efetuadas, e a Tabela 3 apresenta os valores dos coeficientes do modelo potencial das curvas da Figura 1.

Analisando-se a Figura 1, observa-se que o aumento da concentração de sólidos totais de águas residuárias de suinocultura provocou redução na capacidade de infiltração do solo. Aplicações sucessivas intensificaram esta redução, diminuindo o tempo em que a velocidade de infiltração básica igualou-se a zero. Nos testes conduzidos usando-se água residuária com concentração de sólidos totais de $26,9 \mathrm{~g} \mathrm{~L}^{-1}$, houve acúmulo de lodo na superfície do solo, após a segunda época de aplicação, provocando a sua impermeabilização; assim, na condução dos ensaios relativos às $3^{\mathrm{a}}$ e $4^{\mathrm{a}}$ aplicações, a velocidade de infiltração permaneceu nula.
(A) Primeira aplicação

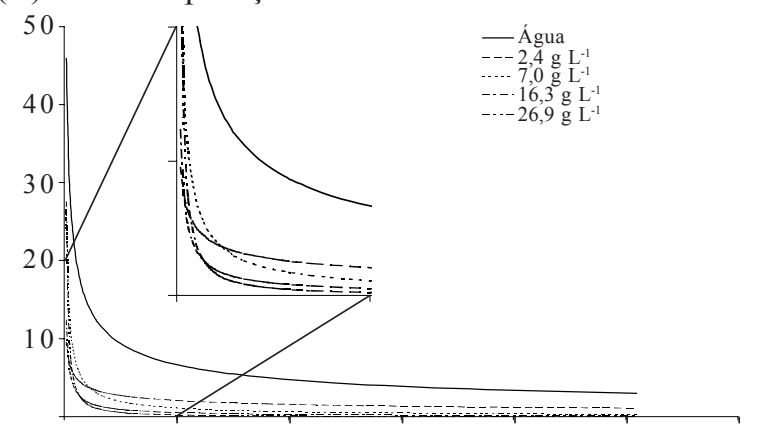

(B) Segunda aplicação

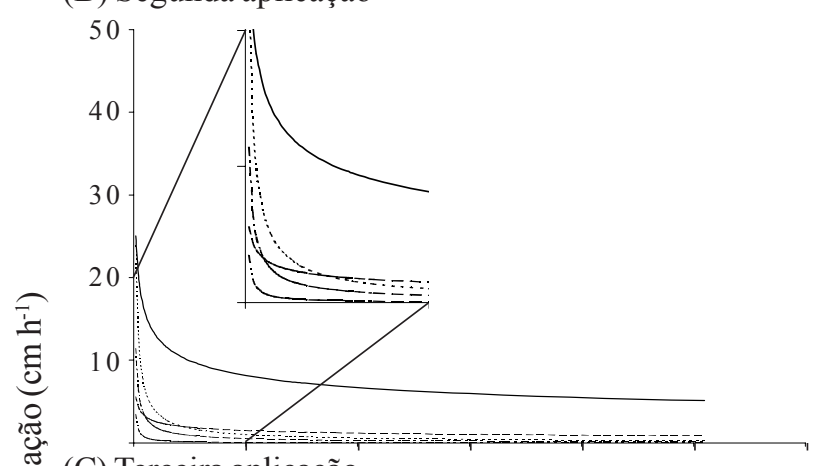

(C) Terceira aplicação

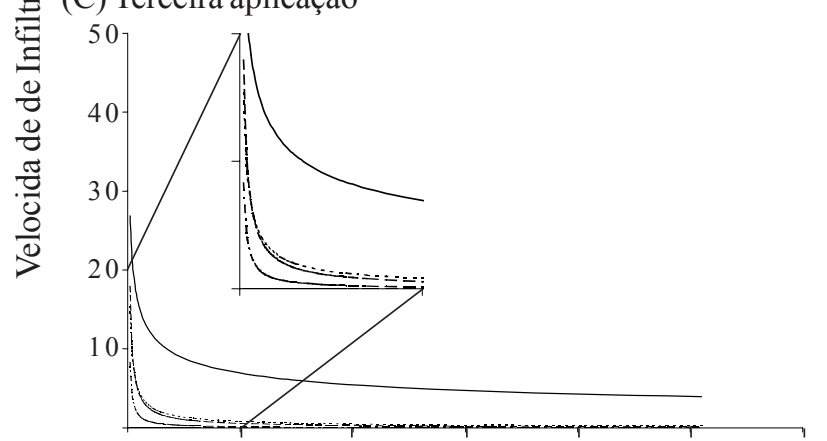

(D) Quarta aplicação

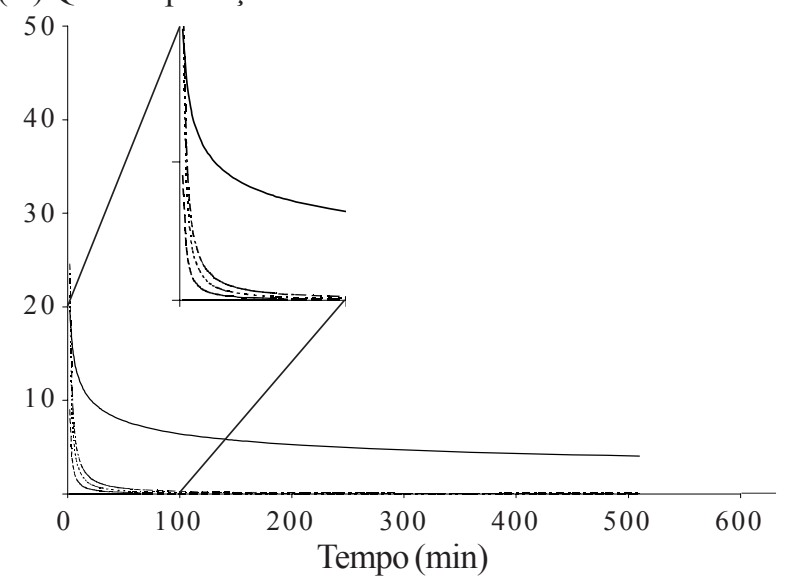

Figura 1. Curvas de velocidade de infiltração em função do tempo para água e águas residuárias nas diversas concentrações de sólidos totais estudadas, por ocasião das primeira (A), segunda (B), terceira (C) e quarta (D) aplicações

A Tabela 4 apresenta os valores médios de velocidade de infiltração básica do solo, para quatro aplicações sucessivas de água e águas residuárias nas diversas concentrações de sólidos totais.

A análise da Tabela 4 mostra que aplicações sucessivas de água residuária no solo ocasionaram selamento superficial, 
Tabela 3. Valores dos coeficientes do modelo potencial relacionando a velocidade de infiltração com o tempo de aplicação, e os respectivos valores do coeficiente de determinação, para as quatro aplicações de água e de águas residuárias de suinocultura, nas diversas concentrações de sólidos totais estudadas

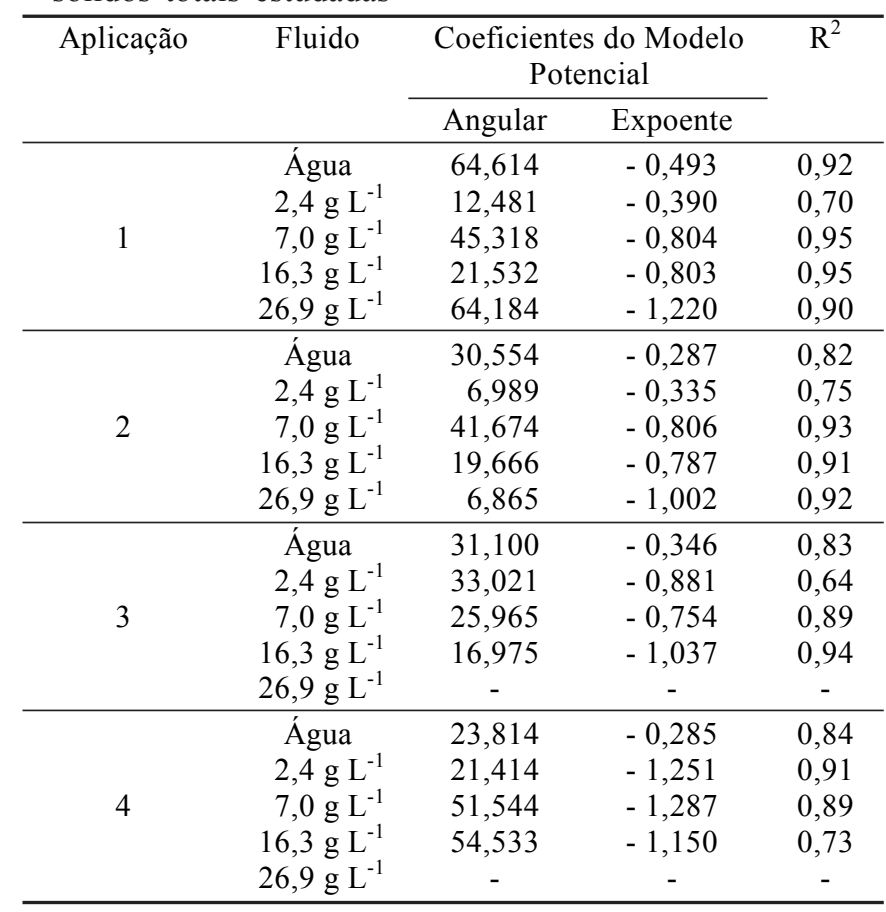

Tabela 4. Valores médios de velocidade de infiltração básica do solo, em $\mathrm{cm} \mathrm{h}^{-1}$, para quatro aplicações sucessivas de água e águas residuárias nas diversas concentrações de sólidos totais estudadas

\begin{tabular}{cccccc}
\hline \multirow{2}{*}{ Aplicação } & \multirow{2}{*}{ Água } & \multicolumn{4}{c}{ Velocidade de Infiltração $-\mathrm{cm} \mathrm{h}^{-1}$} \\
\cline { 3 - 6 } & & \multicolumn{2}{c}{ Concentração de Águas Residuárias $-\mathrm{g} \mathrm{L}^{-1}$} \\
\cline { 3 - 6 } & 2,4 & 7,0 & 16,3 & 26,9 \\
\hline 1 & 4,17 & 1,28 & 0,19 & 0,20 & 0,00 \\
2 & 5,69 & 0,64 & 0,16 & 0,07 & 0,00 \\
3 & 5,09 & 0,00 & 0,14 & 0,02 & 0,00 \\
4 & 4,89 & 0,00 & 0,00 & 0,00 & 0,00 \\
\hline
\end{tabular}

independentemente da concentração de sólidos totais; assim, a aplicação de águas residuárias da suinocultura deve ser associada a práticas agrícolas que promovam a escarificação do solo, visando ao rompimento do selamento superficial e ao aumento da capacidade de infiltração. Para a concentração $26,9 \mathrm{~g} \mathrm{~L}^{-1}$ ocorreu selamento logo na primeira aplicação, em razão do acúmulo excessivo de sedimentos sobre a superfície do solo.

A análise conjunta dos dados das Tabelas 2 e 4, no que se refere a problemas de infiltração, mostra que, no caso de aplicação de águas residuárias da suinocultura, a concentração de sólidos totais é mais importante na redução da capacidade de infiltração do solo que os níveis de RAS e de salinidade; assim, as diretrizes propostas por Ayers \& Westcot (1987) para interpretar a qualidade da água para irrigação, não devem ser usadas para águas residuárias de suinocultura, no que se refere ao potencial de ocasionar problemas de redução da capacidade de infiltração do solo, em razão das diretrizes de Ayers \& Westcot (1987) não incluírem os elementos orgânicos sólidos contidos nas águas residuárias.

\section{CONCLUSÕES}

Os resultados apresentados permitem concluir-se que:

1. O aumento da concentração de sólidos totais de águas residuárias de suinocultura provocou redução na capacidade de infiltração do solo, intensificada com aplicações sucessivas.

2. A concentração de sólidos totais desse efluente foi mais importante na redução da capacidade de infiltração do solo que os níveis de razão de adsorção de sódio e de salinidade.

\section{REFERÊNCIAS BIBLIOGRÁFICAS}

APHA - AMERICAN PUBLIC HEALTH ASSOCIATION. Standard methods for the examination of water and wastewater. New York: APHA, WWA, WPCR, 19.ed., 1995.

AYERS, R.S.; WESTCOT, D.W. La calidad del agua en la agricultura. Roma: FAO, 1987. 174 p.

BERNARDO, S. Manual de irrigação. 6. ed. Viçosa: UFV, Imp. Univ., $1995.657 \mathrm{p}$.

DETAR, W.R. Rate of intake and stream advance for liquid dairy manure in furrows. Transactions of the ASAE, St Joseph, v.23, n.5, p.1171-7, 1980.

MATOS, A.T. de; SEDIYAMA, M.A.N.; FREITAS, S.P. Características químicas e microbiológicas do solo, influenciadas pela aplicação de dejeto líquido de suínos. Revista Ceres, Viçosa, v.44, n.254, p.399-410, 1997.

SCHERER, E.E.; BALDISSERA, I.T.; DIAS, L.R.X. Método rápido para determinação da qualidade fertilizante do esterco líquido de suínos a campo. Agropecuária Catarinense. Florianópolis, v.8, n.2, p.44-51, 1995. 